\title{
S Sinteza
}

Impact of Internet on Business Activities

in Serbia and Worldwide

Uticaj Interneta na poslovanje u Srbiji i

svetu

DOI: 10.15308/SINTEZA-2014-941-947

\section{ANALIZA STABILNOSTI KRETANJA OSNOSIMETRIČNE LETILICE}

\author{
Regodić Dušan ${ }^{1}$, Jerković Damir ${ }^{2}$, Regodić Radomir ${ }^{1}$ \\ ${ }^{1}$ Univerzitet Singidunum, Beograd \\ ${ }^{2}$ Vojna akademija, Ministarstvo odbrane, Republika Srbija
}

\begin{abstract}
:
U radu su prikazani rezultati istraživanja uticaja spoljnih sila na letilicu: gravitacione sile Zemlje, aerodinamičke sile, prenosna inercijalna sile, reaktivne sile i Koriolisove sile. Problem je interesantan jer se analizira sposobnosti tela letilice da u dovoljnoj meri prati pravac brzine translacije, koja je tangenta u svakoj tački na trajektoriji centra mase. Predloženim rešenjem se postiže kvalitetna simulaciju kretanja u programskom rešenju sa šest stepeni slobode kretanja u širokom opsegu polaznih uglova. Proračunom se dobijaju: domet, ordinata, pravac, ugaona brzina, brzina leta i padnog ugla u funkciji promene vremena leta i početnog ugla. Poseban doprinos rada se ogleda u proračunu i analizi stabilnosti leta letilice u funkciji vremena leta i pređenog puta preko koeficijenata žiroskopske i dinamičke stabilnosti na početnom delu i derivacije na zakrivljenom delu putanje i promene napadnog ugla $\alpha(t)$ oko y-ose i ugla klizanja $\beta(t)$ oko z-ose. Primenom navedenog rešenja racionalizuju i pojednostavljuju se postupci istraživanja.
\end{abstract}

\section{Key words:}

klasična osnosimetrična letilica, aerodinamički koeficijenti, elementi putanje, parametri stabilnosti, napadni ugao.

\section{UVOD}

Stabilnost letilice predstavlja sposobnost tela da njegova uzdužna osa simetrije u dovoljnoj meri prati pravac brzine translacije, koja je tangenta u svakoj tački na trajektoriji centra mase [2,3]. Matematički gledano, letilica treba da poseduje takve osobine da neutrališe poremećaje koji izazivaju ovu neusaglašenost. Stabilnost se razmatra uvođenjem kvantitativnih kriterijuma Ljapunova u odnosu na jedan slučaj odabranog neporemećenog kretanja. Statičku stabilnost karakteriše ravnoteža sila i momenata u svakom trenutku leta projektila. Kao kvantitativni pokazatelj se može uzeti stepen preopterećenja. Dinamička stabilnost se ceni na osnovu kvantitativnih kriterijuma Ljapunova: maksimalne vrednosti amplitude neke poremećene veličine u odnosu na nominalnu, vremena prigušenja-trajanja prelaznog procesa, periodičnost i aperiodičnosti, itd $[2,3]$.
Kod klasičnih letelica stabilizacija se vrši na osnovu mogućnosti projektila da rotira velikom ugaonom brzinom, čime se obezbeđuje oscilatoran karakter promene veličina stanja poremećenog kretanja. Promene amplitude oscilatornog kretanja u vezi su sa problemom dinamičke stabilnosti, i zavise od momenta i sila koje deluju na letili$\mathrm{cu}, \mathrm{u}$ prvom redu od prigušnog i Magnusovog momenta. U opštem slučaju, zakon o promeni količne kretanja za centar mase osnosimetričnog projektila daje četiri diferencijalne jednačine za oscilovanje projektla oko poprečnih osa aerobalističkog koordinatnog sistema. Kretanje letilice u odnosu na Zemlju je relativno, a uticaj rotacije Zemlje ugaonom brzinom $\Omega_{\mathrm{E}}$ unosi projektilu prenosno kretanje. Brzina kretanja letilice u odnosu na Zemlju VK predstavlja relativnu brzinu, a izvodi njenih komponenata po vremenu predstavljaju komponente relativnog ubrzanja. Rezultantu spoljnih sila koje deluju na projektil čine: 
gravitaciona sila Zemlje, aerodinamička sila, prenosna inercijalna sila, reaktivna sila, i Koriolisova sila. U praksi, zbir gravitacione i prenosne inercijalne sile smatramo silom Zemljine teže ubrzanja $\vec{g}$. Kinetički moment i rezultujući moment spoljnih sila računa se za centar mase letilice. Rezultujući moment čini zbir aerodinamičkog momenta i momenta reaktivne sile u odnosu na centar mase. Sila Zemljine teže i inercijalna Koriolisova sila deluju u centru mase projektila te ne stvaraju momente za centar mase.

Aerobalistički koordinatni sistem se koristi za analizu leta projektila malog dometa (do 20 kilometara). Zanemarujemo rotaciju geodetskog koordinatnog sistema $\mathrm{u}$ odnosu na Zemlju i ugaonu brzinu Zemlje u odnosu na ugaonu brzinu projektila u geodetskom koordinatnom sistemu. Ne zanemaruje se Koriolisova sila i sila Zemljine teže. U radu se polazi od standardnih rešenja za masu, centar mase, položaj osa i momenata inercije [3].

\section{SISTEM DIFERENCIJALNIH JEDNAČINA}

Model kretanja letilice sa šest stepeni slobode čine četiri vektorske jednačine [3]:

- izvod vektora položaja projektila

$$
\frac{\mathrm{d}_{\mathrm{r}} \overrightarrow{\mathrm{r}}}{\mathrm{d}}=\overrightarrow{\mathrm{v}_{\mathrm{k}}}
$$

- vektorska jednačina relativnog kretanja centra masa

$$
m \frac{d_{r} \vec{V}_{k}}{d}=\Sigma \vec{R}
$$

- kretanje oko centra mase

$$
\frac{d H^{g}}{d}=\vec{M}
$$

- veze između ugaonih brzina i izvoda uglova

$$
\vec{\Omega}=\vec{\Omega}_{E}+\vec{\lambda}+\vec{\varphi}+\vec{\psi}+\vec{\theta}+\vec{\Phi}
$$

Projektovanjem vektorskih jednačina leta na aerobalistički koordinatni sistem uz pretpostavku da je tenzor inercije redukovan $\left(\mathrm{I}_{\mathrm{Y}}=\mathrm{I}_{\mathrm{Z}}\right)$ dobija se:

- izvod vektora položaja

$$
\left[\begin{array}{c}
\dot{x} \\
\dot{y} \\
\dot{z}
\end{array}\right]=L_{\mathscr{B}}\left[\begin{array}{l}
u_{k} \\
\approx \\
v_{k} \\
\approx \\
w_{k}
\end{array}\right]
$$

- šest skalarnih jednačina

$$
\begin{aligned}
& \dot{u}_{k}=\tilde{q} w_{k}-\approx \tilde{r} v_{k}+\frac{\left(X+F_{x}\right)}{m}-g \sin \theta-a_{\alpha} \\
& \dot{u}_{k}=\tilde{q} \approx \tilde{w} w_{k}-\tilde{r} v_{k}+\frac{\left(X+F_{x}\right)}{m}-g \sin \theta-a_{\alpha} \\
& \dot{u}_{k}=\approx \approx q w_{k}-\tilde{r} v_{k}+\frac{\left(X+F_{x}\right)}{m}-g \sin \theta-a_{\alpha} \\
& \dot{p}=\frac{\left(L+L^{F}\right)}{I_{x}} \\
& \approx \tilde{q}=p_{b} \tilde{\tilde{r}}+\frac{\left(-I_{x} p \tilde{r}+\tilde{M}+\tilde{M}^{F}\right)}{I_{y}} \\
& \tilde{q}=p_{b}{ }^{r}+\frac{\left(-I_{x} p \tilde{r}+\tilde{M}+\tilde{M}^{F}\right)}{I_{y}}
\end{aligned}
$$

- tri jednačine izvoda uglova stava

$$
\begin{aligned}
& \dot{\Phi}=\mathrm{p}+\tilde{\mathrm{r}} \mathrm{g} \theta \\
& \dot{\theta}=\tilde{\mathrm{q}} \\
& \dot{\psi}=\frac{\tilde{\mathrm{r}}}{\cos \theta}
\end{aligned}
$$

pri čemu su:

$\mathrm{V}_{\mathrm{k}}=\left[u_{k}, \quad \tilde{v_{k}}, \quad \tilde{w_{k}}\right]^{T}$-komponente relativne brzine projektila, $\Omega^{b}=\left[\begin{array}{ccc}p & \tilde{q} & \tilde{r}\end{array}\right]^{T}$-komponente ugaone brzine, $R=\left[\begin{array}{ccc}X & \tilde{Y} & \tilde{Z}\end{array}\right]^{T}$-komponente aerodinamičke sile, $F=\left[\begin{array}{lll}F_{x} & F_{y} & F_{z}\end{array}\right]^{T}$-komponente reaktivne sile, $M^{a}=\left[\begin{array}{ccc}L & \tilde{M} & \tilde{N}\end{array}\right]^{T}$ - komponente aerodinamičkog $M^{F}=\left[\begin{array}{lll}L^{F} & M^{F} & N^{F}\end{array}\right]^{T}$-komponente reaktivnog 


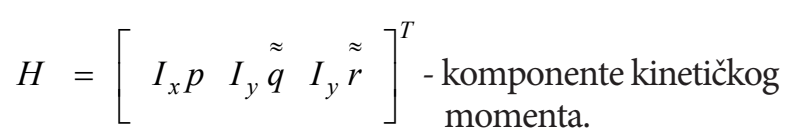

Ovim diferencijalnim jednačinama neophodno je pridružiti algebarsku jednačinu

$$
p_{b}=\stackrel{\approx}{r \operatorname{tg} \theta}
$$

komponente Koriolisovog ubrzanja u aerobalističkom koordinatnom sistemu

$$
a=\left[\begin{array}{l}
a_{\alpha} \\
a_{y} \\
a_{c}
\end{array}\right]=2 \Omega_{E}^{\tilde{b}} V_{k}
$$

Za rotiraju\}i projektil malih dometa vektor stawa sadrži dvanaest komponenata:

$$
\left[\mathrm{x}, \mathrm{y}, \mathrm{z}, \mathrm{u}_{\mathrm{k}}, \underset{\mathrm{v}_{\mathrm{k}}}{\approx}, \underset{\mathrm{w}_{\mathrm{k}}}{\approx}, \mathrm{p}, \mathrm{q}, \underset{\mathrm{r}}{\approx}, \Phi, \theta, \psi\right]
$$

\section{SISTEM JEDNAČINA ZA STABILNOST LETA}

Teorija stabilnosti ne može posmatrati stabilnost projektila, već nekog njenog parametra-funkcije kretanja $[1,3]$. Pri proučavanju dinamičke stabilnosti uvodi se kompleksna bočna brzina $\mathrm{z}$ i kompleksni bočni ugao $\mathrm{x}$.

$$
\begin{array}{r}
\tilde{\approx}=\underset{\sim}{\approx}+i w \\
\xi=\tilde{\beta}+i \alpha
\end{array}
$$

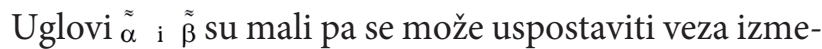
đu kompleksne bočne brzine i kompleksnog bočnog ugla:

$$
\xi=\frac{\approx \tilde{v}+i \tilde{w}}{V}=\frac{\zeta}{V}
$$
zini

Diferencijalna jednačina po kompleksnoj bočnoj br-

$$
\zeta^{\prime \prime}+(H+i P) \zeta^{\prime}-(M+i P T) \zeta=i A+i E+G
$$

pri čemu leva strana jednačine predstavqa homogeni a desna nehomogeni (prinudni) deo, a ostale veličine predstavljaju koeficijente $\mathrm{H}, \mathrm{P}, \mathrm{M}$ i T: aerodinamička nesimetrija,

$$
\begin{aligned}
& -\frac{\left(C_{m q}^{*}+\gamma C_{m \dot{\sigma}}^{*}\right)}{r_{y}^{* 2}} \\
& P=\frac{I_{x}}{I_{y}} \cdot \frac{p \cdot d}{V}, \\
& \mathrm{M}=\frac{\gamma\left(\mathrm{C}_{\mathrm{m} \sigma}-\mathrm{C}_{-}, \frac{\mathrm{V}^{\prime}}{\mathrm{m} \sigma}\right)-\mathrm{C}_{\mathrm{mq}} \mathrm{C}_{-}}{\mathrm{r}_{\mathrm{y}}^{* 2}} \mathrm{i} \\
& \mathrm{T}=-\mathrm{C}_{\mathrm{z} \sigma}+\frac{\gamma \mathrm{C}_{-}}{\mathrm{r}_{\mathrm{x}}^{* 2}} \text {. } \\
& \mathrm{A} \frac{\mathrm{V}\left(\mathrm{C}_{--}+\mathrm{iC}_{-}\right)}{\mathrm{r}_{\mathrm{y}}^{* 2}}
\end{aligned}
$$

- poprečni reaktivni moment,

$$
E=\frac{M^{F}+i N^{F}}{m v} \cdot \frac{1}{r_{y}^{* 2}}-i\left[\frac{\left(F_{y}+F_{z}\right) d}{m v}\right]^{\prime}
$$

- $\quad$ moment nastao zbog ubrzanja Zemljine teže,

$$
G=i \frac{g d \cos \theta}{V}\left[\frac{v^{\prime}}{V}+\frac{C_{\bar{m} q}}{r_{y}^{* 2}}+i P\right]
$$

- bezdimenzionalni poluprečnici,

$$
\begin{aligned}
& r_{y}^{* 2}=\frac{r_{y}}{d} ; r_{y}^{*}=\frac{\sqrt{\frac{I_{y}}{m}}}{d} \\
& \gamma=\frac{u}{V}
\end{aligned}
$$

- Veličine označene sa "*” predstavljaju stvarne vrednosti pomnožene sa $\mathrm{E}=\rho \mathrm{Sd} / 2 \mathrm{~m}$.

Veličine $\mathrm{M}, \mathrm{P}, \mathrm{H}, \mathrm{i}$ T mewaju se sa promenom masenih karakteristika i derivativa aerodinamičkih koeficijenata sa promenom Mahovog broja. Derivativi aerodinamičkih koeficijenata su sporo promenljive funkcije pređenog puta. Ova osobina omogućuje "zamrzavanje" derivativa aerodinamičkih koeficijenata na određenom delu putanje. $\mathrm{Na}$ osnovu toga zaključujemo da se homogeni deo jednačine može analizirati kao diferencijalna jednačina sa konstantnim koeficijentima. Izvod kompleksne brzine: 


$$
\begin{gathered}
\zeta^{\prime}=\xi^{\prime} v+\xi v^{\prime} \\
\zeta^{\prime \prime}=\xi^{\prime \prime} v+2 v^{\prime} \xi^{\prime}+\xi v^{\prime \prime}
\end{gathered}
$$

Smenom u 10 dobija se diferencijalna jednačina po kompleksnom napadnom uglu:

$$
\xi^{\prime \prime}+\left(H+2 \frac{v^{\prime}}{v}-i P\right) \xi^{\prime}-\left[(M+i P T)-(H-i P T) \frac{v^{\prime}}{v}-\frac{v^{\prime \prime}}{v}\right] \xi=i A_{1}+i E_{1}+G_{1}
$$

pri čemu su:

$$
\begin{aligned}
& A=\frac{V\left(C_{--}+i C_{-}\right)}{r_{y}^{* 2}} \text { - aerodinamička nesimetrija, } \\
& E=\frac{M^{F}+i N^{F}}{m v} \cdot \frac{1}{r_{y}^{* 2}}-i\left[\frac{\left(F_{y}+F_{z}\right) d}{m v}\right]^{\prime} \text {-poprečni }
\end{aligned}
$$

reaktivni moment i

$$
\mathrm{G}=\mathrm{i} \frac{\mathrm{gd} \cos \theta}{\mathrm{V}}\left[\frac{\mathrm{v}^{\prime}}{\mathrm{V}}+\frac{\mathrm{C}_{\overline{\mathrm{m}} \mathrm{q}}}{\mathrm{r}_{\mathrm{y}}^{\mathrm{y}^{2}}}+\mathrm{iP}\right] \text {-moment nastao }
$$

zbog ubrzanja Zemljine teže.

Izbor kompleksne poprečne brzine projektila kao parametra čija se stabilnost ispituje omogućava izvođenje kriterijuma stabilnosti. Rešenje diferencijalne jednačine sastoji se od homogenog i partikularnog integrala. Homogena diferencijalna jednačina imaće oblik:

$$
\zeta^{\prime \prime}+(H+i P) \zeta^{\prime}-(M+i P T) \zeta=i A+i E+G
$$

Rešenje homogene diferencijalne jednačine određuje se karakterističnom jednačinom:

$$
\mathrm{r} 2+(\mathrm{H}-\mathrm{iP}) \mathrm{r}-(\mathrm{M}+\mathrm{iPT})=0
$$

Rešenje homogene diferencijalne jednačine imaće oblik:

$$
\zeta_{\mathrm{h}}=\mathrm{Z}_{1} \mathrm{e}^{\mathrm{i} \Phi_{1}}+\mathrm{Z}_{2} \mathrm{e}^{\mathrm{i} \Phi_{2}}
$$

pri čemu su:

$$
\begin{aligned}
& Z_{j}=Z_{j 0} e^{\lambda_{j} s^{*}}, \mathrm{j}=1,2 \\
& \Phi_{j}=\Phi_{j 0}+\Phi_{j i} s^{*}, \mathrm{j}=1,2 \\
& \mathrm{r}_{\mathrm{j}}=\lambda_{\mathrm{j}}+\mathrm{i} \Phi_{\mathrm{j}}=\frac{\mathbf{1}}{\mathbf{2}}\left[-\mathrm{H}+\mathrm{iP} \pm \sqrt{4 \mathrm{M}+\mathrm{H}^{2}-\mathrm{P}^{2}+2 \mathrm{P}(2 \mathrm{~T}-\mathrm{H})}\right], \mathrm{j}=1,
\end{aligned}
$$

2.

$$
r_{j}=\frac{1}{2}\left[-H \pm \frac{2 T-H}{\sqrt{1-\frac{1}{S g}}}\right]+i \frac{P}{2}\left[1 \pm \sqrt{1-\frac{1}{S g}}\right], \mathrm{j}=1,2
$$

Da bi $\sqrt{1-\frac{1}{S g}}$ imalo realno rešenje, neophodno je zadovoljiti uslov P2-4M > 0. Na osnovu te pretpostavke mogu se odrediti približni izrazi za frekvenciju i prigušenje:

$$
\begin{aligned}
& \Phi_{j}=\frac{1}{2}\left[P \pm \sqrt{P^{2}-4 M}\right], \mathrm{j}=1,2 \\
& \lambda_{j}=-\frac{1}{2}\left[H \mp \frac{P(2 T-H)}{\Phi_{1}-\Phi_{2}}\right], \mathrm{j}=1,2
\end{aligned}
$$

Uvođenjem oznake:

$$
\frac{1}{S g}=\frac{4 M}{P^{2}} \cong \frac{1}{S g}=\frac{4 M+H^{2}}{P^{2}}
$$

Pri čemu je $4 \mathrm{M} \geq \mathrm{H} 2$, pa se zadržava samo uticajniji član 4M. Da bi kompleksna diferencijalna jedna ina imala re\{ewe, neophodno je

$$
\frac{1}{S g}=\frac{4 M}{P^{2}}<1
$$

što predstavlja uslov žiroskopske stabilnosti. Da bi se ostvarila dinamička stabilnost projektila po bočnoj brzini neophodno je da se amplitude oscilacija približavaju nekoj asimptotskoj vrednosti. Taj uslov je ispuwen ako su vrednosti prigušewa $\lambda 1<0$ i $\lambda 2<0$.

Rešenjem nejednačine

$$
\lambda_{1}=-H+\frac{2 T-H}{\sqrt{1-\frac{1}{S g}}}<0
$$

uvođenjem oznake

$$
S d=\frac{2\left(T+C_{x}^{*}\right)}{H+2 C_{x}^{*}}
$$

dobija se uslov dinamičke stabilnosti projektila

$$
\frac{1}{S g}<S d(2-S d),
$$

a jednačina granične krive stabilnosti je definisana izrazom

$$
\frac{1}{S g}<S d(2-S d) \text {. }
$$

Rešenjem homogene diferencijalne jednačine po kompleksnoj bočnoj brzini dobija se isti uslov kao i rešenjem po kompleksnom bočnom uglu. 


\section{KONCEPCIJA PROGRAMSKOG REŠENJA}

Programsko rešenje „PROGRAM SB06.FOR” za personalni računar, napravljeno je u programskom jeziku FORTRAN, i sastoji se od četiri celine [2]:

1. Datoteka SB06U. DAT.- ulazna datoteka

2. Program SB06. FOR. - glavni program

3. Datoteka SB061. DAT.- izlazna datoteka.

4. Datoteka SB062. DAT.- izlazna datoteka.

Program SB06.FOR namenjen je za detaljan spoqnobalistički proračun i simulaciju leta rotirajućeg projektila sa reaktivnom silom i bez nje. Prema jednoj opciji program proračunava karakteristične parametre stabilnosti leta projektila. Integracija diferencijalnih jednačina vrši se metodom Runge-Kuta sa četiri približenja.

Tačnost proračuna zavisi od: koraka integracije, tačnosti i broja derivativa aerodinamičkih koeficijenata, definisane brzine vetra i reaktivne sile.

Sadržaj ulazne datoteke SB06U. DAT:

T0, H,TK, XK, ZK

T1, T2, NDT, NSTAB

VW0, DVW, AWOS, DAWS, FW, HIOS

$$
\begin{aligned}
& (\mathrm{X}(\mathrm{K}), \mathrm{K}=1,3) \\
& (\mathrm{X}(\mathrm{K}), \mathrm{K}=4,6) \\
& (\mathrm{X}(\mathrm{K}), \mathrm{K}=7,9)
\end{aligned}
$$

FIOS, TETAOS, PSIOS

Datoteke SB061.DAT i SB062.DAT kreiraju se u toku izvođenja programa. Naredbom WRITE programa SB06. FOR, u wih se smeštaju dobijene informacije. To su rezultati spoljno balističkog proračuna predstavljeni tabelarnim izlaznim vrednostima.

Na slici 1. je prikazan algoritam programskog rešenja.

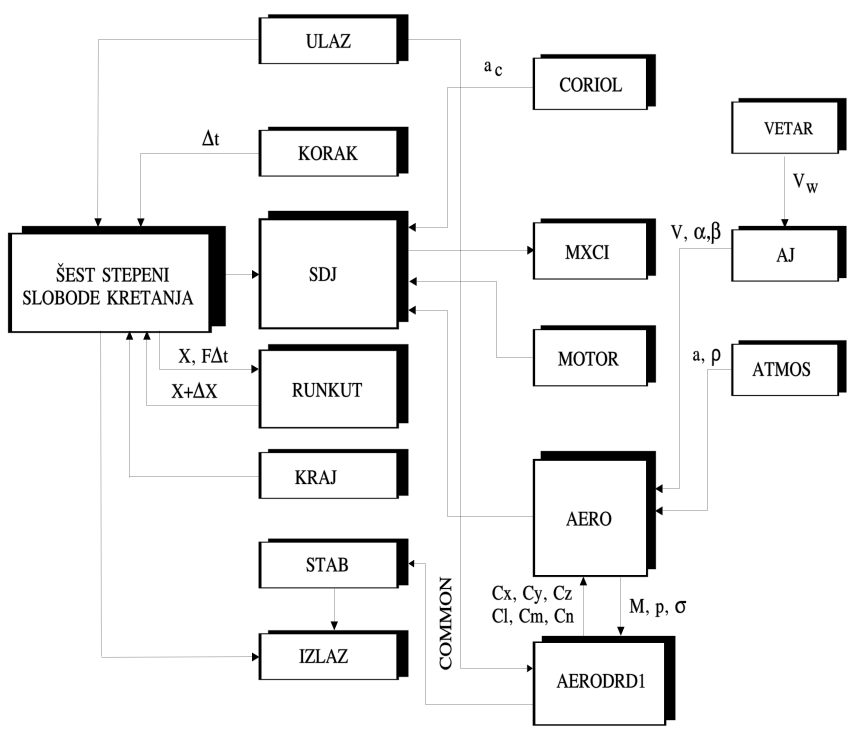

Sl.1. Algoritam programskog rešenja [2]
Polazni podaci za datoteku „SB06U.DAT” [2]

$\mathrm{T} 0=0[\mathrm{~s}] 4 ; \mathrm{H}=0.001[\mathrm{~s}] ; \mathrm{TK}=270.5[\mathrm{~s}] ; \mathrm{XK}=25000[\mathrm{~m}] ;$ $\mathrm{ZK}=0[\mathrm{~m}]$

$\mathrm{T} 1=0.00[\mathrm{~s}] ; \mathrm{T} 2=15[\mathrm{~s}] ; \mathrm{NDT}=10 ; \mathrm{NSTAB}=0 ;$

$\mathrm{VWX}=0[\mathrm{~m} / \mathrm{s}] ; \mathrm{VWY}=0[\mathrm{~m} / \mathrm{s}] ; \mathrm{VWZ}=0[\mathrm{~m} / \mathrm{s}] ;$

$\mathrm{X}(1)=0[\mathrm{~m}] ; \mathrm{X}(2)=0[\mathrm{~m}] ; \mathrm{X}(3)=0[\mathrm{~m}] ;$

$\mathrm{X}(4)=810[\mathrm{~m} / \mathrm{s}] ; \mathrm{X}(5)=0[\mathrm{~m} / \mathrm{s}] ; \mathrm{X}(6)=0[\mathrm{~m} / \mathrm{s}] ;$

$\mathrm{X}(7)=1675.334[1 / \mathrm{s}] ; \mathrm{X}(8)=1.034811[1 /$

s];X(9) $=7.726234[1 / \mathrm{s}]$;

FIOS $=0\left[^{0}\right] ;$ TETA0S $=65\left[^{0}\right] ;$ PSIOS $=0\left[^{0}\right]$.

Na slici 2. prikazana je promena ordinate y putanje pri različitim dometima letilice $\mathrm{x}$.

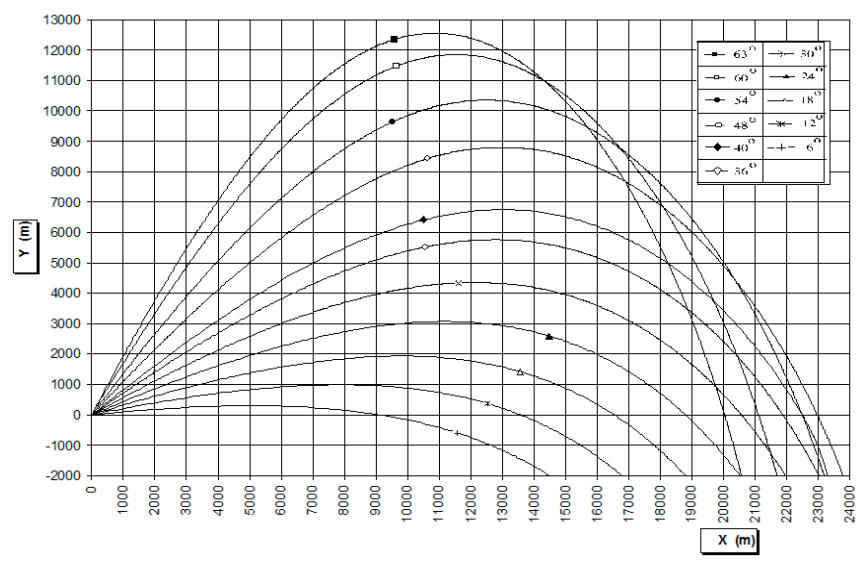

Sl. 2. Promena ordinate putanje $\mathrm{x}=\mathrm{f}(\mathrm{y}) \mathrm{u}$ funkciji promene polaznih uglova za hipotetički projektil $152 \mathrm{~mm}$

Na slici 3. prikazana je napadnog ugla $\alpha$ u funkciji promene ugla klizanja $\beta$ na putanji.

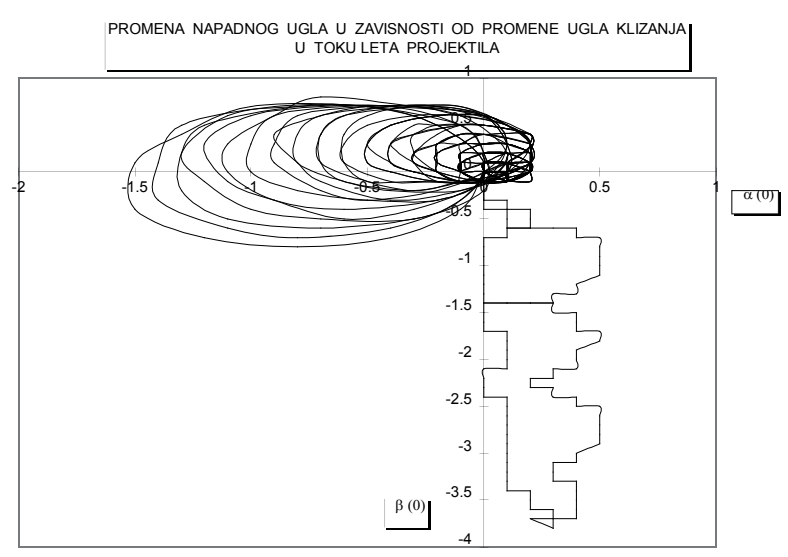

Sl. 3. Promena napadnog ugla $\alpha$ u funkciji promene ugla klizanja $\beta$ na putanji 
Na slici 4. prikazana je promena napadnog ugla $\alpha$ i ugla klizanja $\beta$ na putanji do odstojanja $76 \mathrm{~m}$ od usta cevi.

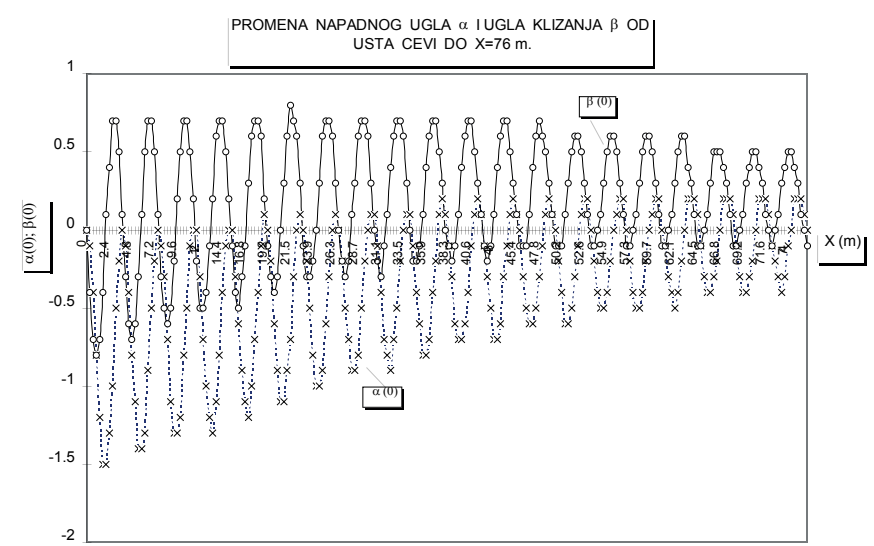

Sl. 4. Promena napadnog ugla $\alpha$ i ugla klizanja $\beta$ na putanji do odstojanja $76 \mathrm{~m}$ od usta cevi

Na slici 5. prikazana je promena napadnog ugla $\alpha \mathrm{i}$ ugla klizanja $\beta$ na putanji u vremenu $t=21,5 \mathrm{~s} . \breve{E} 104 \mathrm{~s}$.

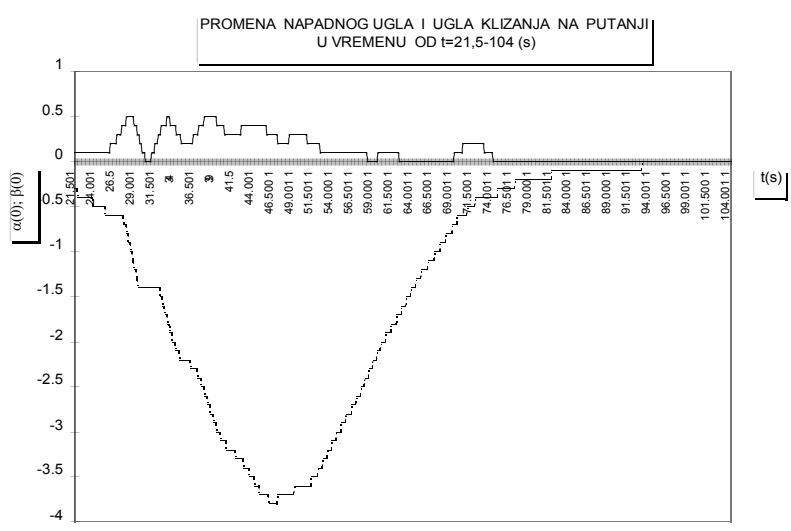

Sl. 5. Promena napadnog ugla $\alpha$ i ugla klizanja $\beta$ na putanji u vremenu $\mathrm{t}=21,5 \mathrm{~s} . \breve{\mathrm{E}} 104 \mathrm{~s}$

Na slici 6. prikazana je promena napadnog ugla $\alpha \mathrm{u}$ toku leta projektila.

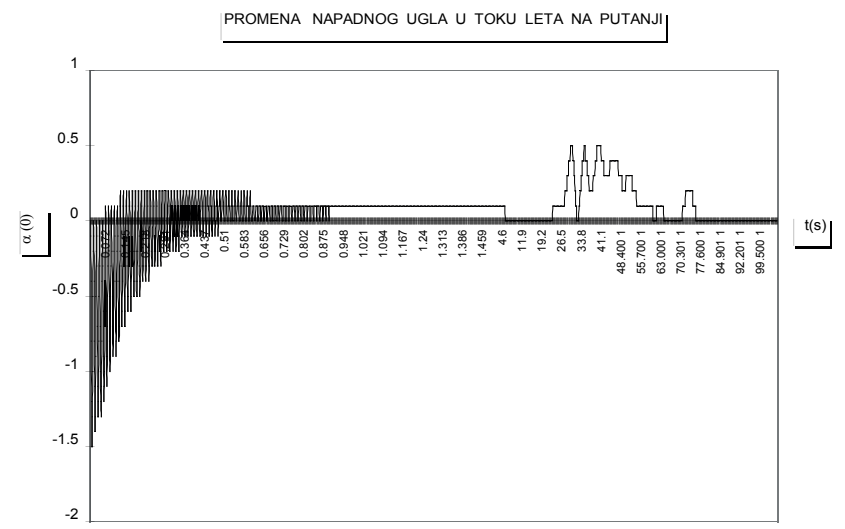

Sl. 6. Promena napadnog ugla $\alpha \mathrm{u}$ toku leta projektila
Na slici 7. prikazana je promena ugla klizanja $\beta$ u toku leta letilice

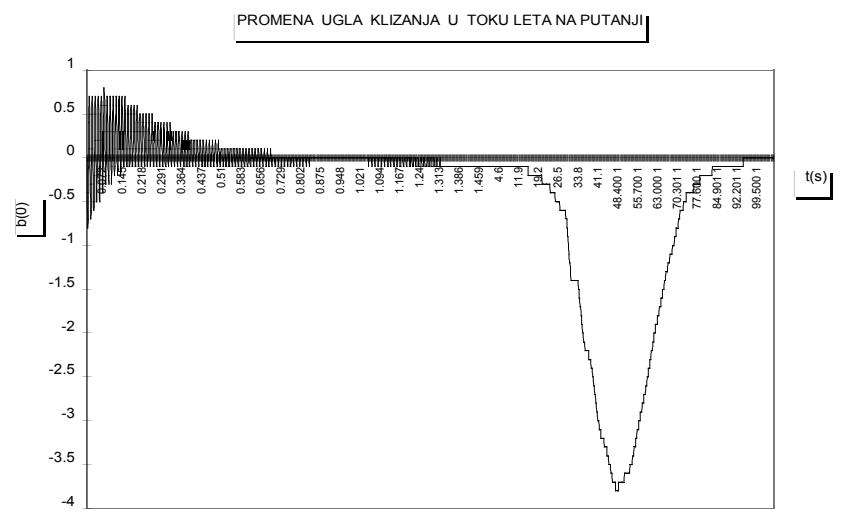

Sl. 7. Promena ugla klizanja $\beta$ u toku leta letilice

\section{ZAKLJUČAK}

Simulacijom kretanja u programskom rešenju sa šest stepeni slobode kretanja u širokom opsegu polaznih uglova, omogućuje proračun stabilnosti leta i elementa putanje letilice. Kriva zavisnosti ordinate y u odnosu na horizontalnu daljinu $\mathrm{x}$ ima identičan karakter promene $[1,3]$.

Parametri stabilnosti kretanja osnosimetrične letilice zavise i od vrednosti derivativa aerodinamičkih koeficijenta. Proračun je pokazao da karakter promene napadnog ugla $\alpha$ i ugla klizanja $\beta$ za vrednosti proračunskih i eksperimentalnih derivativa se razlikuje po frekvenciji prigušenja i amplitudi oscilovanja, posebno na prvom delu putanje. Na osnovu proračuna se vidi da je zadovoljen teorijski kriterijum stabilnosti leta:da su realni delovi korena $\lambda 1$ i $\lambda 2$ negativni $[3,9]$. Posledica toga je smanjenje zbira ta dva vektora, a time i napadnog ugla i međusobno približavanje ose projektila i brzine leta. Amplitude promene napadnih uglova smanjuju se tokom leta, što dokazuje stabilnost kretanja letilice i za proračunske i iz eksperimentalnih rezultata izračunate derivative. Uslov stabilnosti je zadovoljen ako je ispunjen uslov:

$$
H>0 i \frac{1}{S_{g}}<S_{d}\left(2-S_{d}\right)
$$

Većina letilica se može razvrstati u:

- statički stabilne bez rotacije oko uzdužne ose ili sprorotirajuće,

- statički nestabilne koji moraju biti žiroskopski stabilisani.

Osnovne karakteristike statički stabilnih letilica: žiroskopski su stailisani bez obzira na rotaciju oko uzdužne ose; ukoliko se faktor dinamičke stabilnosti nalazi u intervalu $0<S_{d}<2$, statički stabilna letilica je uvek i dinamički stabilna, bez obzira na rotaciju oko uzdužne ose; za vrednosti faktora dinamičke stabilnosti $0>S_{d}>2$, velika ugaona brzina oko uzdužne ose $(p)$ učiniće statički stabilne letilce dinamički nestabilnim.

Osnovne karaktieristike statički nestabilnih letilica su:

- žiroskopska stabilnost je neophodan, ali i nedovoljan uslov za dinamičku stabilnost; 
- pri vrednostima faktora dinamičke stabilnosti statički nestabilna letilica je uvek stabilna. Vrednost uzdužne rotacije određenom ugaonom brzinom neophodnom za dinamičku stabilnost dobija se iz uslova:

$p^{2}>\frac{4 M}{S_{d}\left(2-S_{d}\right)}$,

gde je:

$P=\left(\frac{I_{x}}{I_{y}}\right) \cdot\left(\frac{p d}{V}\right)$

- za vrednost dinamičkog faktora stabilnosti statički nestabilna letilica ne može postati dinamički stabilan bez obzira na vrednost uzdužne ugaone brzine $\mathrm{p}$;

- za statički nestabilne letilice uslov dinamičke stabilnosti je:

$$
\frac{1}{S_{g}}<S_{d}\left(2-S_{d}\right)
$$

Na slici 8. dat je grafički prikaz odnosa žiroskopske i dinamičke stabilnosti letilice sa ugaonom brzinom p oko uzdužne ose letilice $[1,5]$.

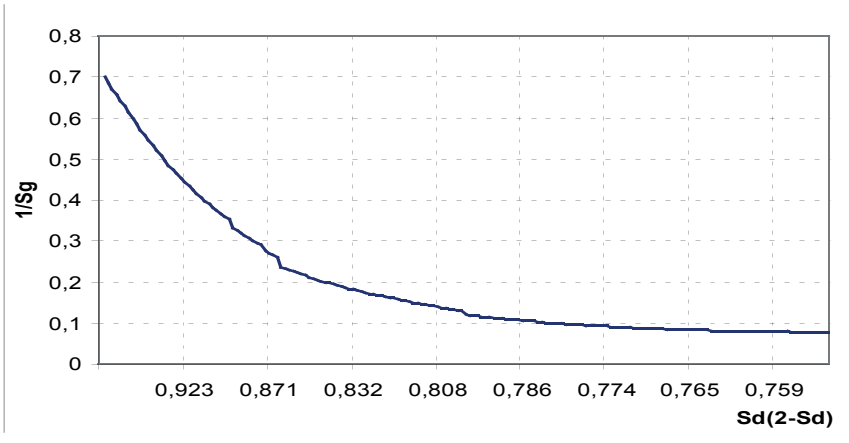

Sl.8. Međusobna zavisnost koeficijenta $1 / \mathrm{S}_{\mathrm{g}}$ i $\mathrm{S}_{\mathrm{d}}\left(2-\mathrm{S}_{\mathrm{d}}\right)$

Na osnovu dobijenih vrednosti na slici 8 . Može se zaključiti:

- za vrednost koeficijenta dinamičke stabilnosti $0,8<S d<1,2$ dovoljan je uslov $S g>1$ za dinamičku i žiroskopsku stabilnost;
- ako je koeficijent dinamičke stabilnosti $S_{d}=0,5$ (ili $\left.S_{d}=1,5\right)$, tada bi $S_{g}$ moralo biti veće od 1,33 da bi se osigurala dinamička stabilnost;

- za vrednost $S_{d}=0,1$ (ili $\left.S_{d}=1,9\right)$ letilica bi bila dinamički stabilna ako je $S_{g}>5,26$.

Keller, Reno i Mc Shane smatraju da se jednačina (16) može smatrati "pojačanjem" kriterijuma klasične žiroskopske stabilnosti $\left(S_{g}>1\right)$ trži se da je

$$
S_{g}>\frac{1}{S_{d}\left(2-S_{d}\right)}
$$

koja je zbog svog oblika uvek veća od jedinice. Sa slike 8. se vidi da je osnovni problem definisanja ugaone brzine rotacije letilice zasnovan samo na klasičnom zahtevu $S_{g}>1$.

\section{LITERATURA}

[1] Regodić, D., Reverzibilni proračun putanje projektila primenom modela sa šest stepeni slobode kretanja, Vojnotehnički glasnik, vol. 46, br. 5, pp. 527-538,

[2] Regodić, D., Zbirka zadataka iz spoljne balistike, UŠIO, Beograd, 2003.

[3] Regodić, D., Spoljna balistika, Vojna akademija, Beograd, 2006.

[4] Regodić, D., Uticaj vrste strujanja na ukupni aerodinamički koeficijent, Vojnotehnički glasnik, vol. 43, br. 1, ISSN 0042-8469, UDC 623+355/359, pp.52-64, Beograd, 1995.

[5] Jerković, D., Uticaj aerodinamičkih koeficijenata na kretanje osnosimetričnog tela, magistarska teza, Fakultet tehničkih nauka, Novi Sad, 2009.

[6] Tablice gađanja za PAT $40 \mathrm{~mm}$ L/70 Bofors, SSNO, Beograd, 1982.

[7] Tehničko uputstvo za brodski PAT $40 \mathrm{~mm}$ D70 M55m i M70 Bofors, knjiga 1, SSNO, Beograd, 1975.

[8] Range tables for $40 \mathrm{~mm}$ Automatic Gun L-70, AB Bofors, Sweden.

[9] Ćuk, D., Uticaj povećanja dometa na dinamičku stabilnost artiljerijskih raketa sa olučastim krilima, Vojnotehnički glasnik, vol. 55, br. 3, pp.296-307,ISSN 0042-8469, UDC 623+355/359, Beograd, 2007.Beograd, 1998.

\section{STABILITY ANALYSIS OF AXISYMMETRIC SPACECRAFT MOTION}

\section{Abstract:}

This paper presents the results of research on the effects of external forces on the spacecraft: the gravitational force of the Earth, aerodynamic forces, portable inertial forces, reaction forces and the Coriolis force. The problem is interesting because it analyzes the ability of the body to the spacecraft to sufficiently monitor the direction of the speed of translation, which is the tangent at each point of the trajectory of the center of mass. The proposed solution achieves a high-quality movement simulation in the programming solution with six degrees of freedom in a wide range of initial angles. The calculation providies the following: the range, ordinate, straight/direction, angular velocity, the speed of flight and falling angle, in the function of flight time and initial angle changes. A special contribution of the work is reflected in the calculation and analysis of the stability of the flight, in the function of flight time and covered distance, via the coeficient of gyroscopic and dynamic stability, at the starting point, and the derivative at the curved part of the path, as well as the changes of the angle of attack $\alpha(t)$ around the $y$-axis, and the slip angle $\beta(t)$ around the $z$-axis. By applying the above solutions, the procedures of research become racionaliyed and simplified.

\section{Key words:}

the classic axisymmetric

spacecraft, aerodynamic coefficients, path element, stability parameters, the angle of attack. 